\title{
Influence of changes in hip bone morphology and anterior knee pain
}

\author{
Hugo Machado Sanchez ${ }^{1}$, Layla Rosa de Castro², Beatriz Santana Borges ${ }^{3}$, Eliane Gouveia de Morais Sanchez ${ }^{4}$,
} Jair Pereira de Melo Junior ${ }^{5}$

\begin{abstract}
Introduction: The patellofemoral pain syndrome (PFPS) is one of the most common disorders of the knee, and there is still unclear etiology. Objective: The aim of this study was to correlate patellofemoral pain syndrome with the bone morphology of hip. Method: For this, this study evaluated 31 studied volunteers with aged between 18 and 30 years, which analyzed the distance of anterior superior iliac spines (ASIS), asymmetry of the pelvis, lower limb length (LL), distance from the ASIS bilaterally of the patella, lateral tilt and iliac inclination, this by computerized biophotogrammetry. Results: After collecting the data and consequent tabulation, it was found that were no changes in the data collected except in the lateral tilt, so the volunteers who had anterior knee pain also had lateral pelvic tilt. Conclusion: That said, we can infer that there is little relationship between the morphological changes of the hip with the PFPS, whereas found only one was in lateral pelvic tilt voluntary group who complained of pain above the knee.
\end{abstract}

KEYWORDS: PFPS, morphology, pelvis, hip, knee.

\section{INTRODUCTION}

The knee is a synovial joint, which is classified as a hinge joint being formed by the union of three joints, two tibiofemoral joint and the patellofemoral joint. All of them are contained within just one joint capsule. Although it is a hinged joint, it still has $6^{\circ}$ freedom in a three-axis system. ${ }^{(1)}$

The bone structures which compound the knee joints are: tibia, femur and patella. These joints can not be considered separately, since there is a mechanical system between them. ${ }^{(2)}$ The patella has the function of protecting the anterior surface of the femur as well as increasing the efficiency of the quadriceps muscles. The patella has in its articular surface two facets, medial and lateral. They are divided by a prominence called the vertical crest. Each of these facets may be further subdivided, the medial facet subdivided into four, and the lateral facet subdivided into three. ${ }^{(1)}$

The mechanism of the patellofemoral joint is greatly influenced by its static and dynamic stabilizers. A dynamic stabilizer of this joint is the quadriceps muscle as well as the pes anserine muscles and the femoral biceps, as they control the external and internal rotation of the tibia. Static stabilizers include: the extensor retinaculum, the iliotibial tract, the patellar tendon, and the quadriceps tendon. ${ }^{(1)}$
The hip is formed by the union of three bones: ilium, pubis and ischium. The right and left hips join posteriorly with the sacrum and anteriorly with the pubic symphysis. The sacrum and hips form the pelvis. In Latin, pelvis means "basin".(3)

Patellofemoral pain syndrome (PFPS) is defined as a painful disorder of the knee joint, which results from poor patellar alignment. ${ }^{(4)}$ Cabral et al. ${ }^{(5)}$ report that patellofemoral pain syndrome is characterized by peripatellar or retropatellar pain which affects athletes and non-athletes and represents a common problem in the knee of young and physically active adults.

The main symptom of this syndrome is the diffuse pain in the anterior region of the knee, and these effects cause functional damage to the individuals who are affected. Initially, it affects mainly young women. The symptoms intensify when there are some activities such as running, crouching, up or down stairs or even staying in the sitting position for a long time. ${ }^{(4)}$

Cabral, et al. ${ }^{(5)}$ believe that the etiology is related to increased $Q$ angle, which results from poor patellar alignment, or also high, low patella, femoral anteversion, lateral rotation of the tibia or even excessive subtalar pronation. 
Through the $\mathrm{Q}$ angle it is possible to diagnose some patellofemoral changes. Any angle above $17^{\circ}$ is considered excessive, so it is called genu valgum. Whereas an angle less than $10^{\circ}$ should be considered genu varum. Most men have a $Q$ angle $10^{\circ}$ to $14^{\circ}$, while in women this angle is $15^{\circ}$ to $17^{\circ}$ because the woman has the widest pelvis. ${ }^{(6)}$

According to Mascal, Landel and Christopher ${ }^{(7)}$, weakness or retraction of the pelvic muscles, as well as the alteration of the pelvic morphology, influence the alignment of the lower limb, thus contributing to the occurrence of patellofemoral pain.

In the studies of Ireland et al. ${ }^{(8)}$ it has been reported that an excessively adducted femur may be a consequence of a wider pelvis, internally rotating the femur during athletic movements, promoting lateral gliding of the patella and increasing lateral retropatellar pressure. They also report that repeated movements with the mentioned slip may cause injury to the retinaculum, the cartilage of the retropatellar joint and the subchondral bone, leading to anterior knee pain.

It is well-known in the literature that pelvic positioning may have a great influence on the action of the rectus femoris muscle, because the origin of this muscle occurs in the antero inferior iliac spine, so that if it has antero superior changes or left-right to the line of action and the force generated by the cited muscle may be altered. ${ }^{(9)}$

Hereafter, the present study aimed to analyze whether changes in pelvic morphology or positioning may trigger anterior knee pain.

\section{METHOD}

This study is a cross-sectional descriptive approach. According to Resolution 466/12 of the National Health Council of the Ministry of Health, this project was submitted to the Research Ethics Committee of the University of Rio Verde UniRV - to approve the procedures to be adopted. The research began only after the approval of the Committee. Respecting the resolution 466/12, at no time were disclosed the identity of the evaluated people, but only the data obtained. The information collected through the evaluation was archived with the researchers.

The field research was conducted at the Clínica Escola de Fisioterapia at UniRV - Rio Verde University, located in the Rio Verde city - Goiás. The target population of this study was composed of 31 academics from the UniRV Physiotherapy Course - University of Rio Verde, aged between 18 and 30 years.

It was included in this study only females who accepted to participate aged between 18 and 30 years old, with knee pain diagnosed by clinician and the researcher, sedentary, who were not in physiotherapeutic treatment and who signed the free and informed consent term.

Exclusion criteria were for those women who were less than 18 or over 30 years old, who practice physical activity, had other injuries associated with ligament injuries, meniscal or osteoarticular and muscle injuries, volunteers who underwent knee or hip surgeries, pregnant women or people with a body mass index (BMI) above $40 \mathrm{~kg} / \mathrm{m}^{2}$, who were in physical therapy, as well as those who have not signed the free and informed consent term.

The data collection occurs after the approval and signing of the of Free and Informed Consent Term, clarifying doubts which could arise in relation to the evaluation that would be applied.

First, the volunteers were instructed to wear gym clothes. Subsequently, they were endangered about the items referring to the evaluation form. Data were collected from that moment. At first, the volunteers were placed in dorsal decubitus, in which the anterior superior iliac spines (ASIS) were marked with adhesive markers. The following items were checked with the tape measure: distance between ASIS, distance from ASIS to patella, and actual length of lower limbs.

After this stage, the volunteers were instructed to stay in the orthostatic position and the ASIS were remarked and the posterior superior iliac spines (PSIS) and the highest point of the iliac crests were demarcated, the marking was done with adhesive spheres. It is important to note that all points have been demarcated bilaterally.

The camera was positioned at a distance of $3 \mathrm{~m}$ from the volunteers, aligned at the height of the iliac crest. After this, two images were taken, the first in anterior view, in order to verify the pelvic tilt/leveling from the ASIS misalignment, the second image in lateral view right and left, to check the iliac inclination of both sides ${ }^{10}$.

For the analysis of the images we used a SAPO ${ }^{\circledR}$ software, which quantifies degrees each angle from the demarcations.

The quantitative data were organized and analyzed for frequency of occurrence and the results were by graphs and tables, using the data tabulation program. The t-test was used to compare the variables between groups. Significant values of p less than 0.05 were considered significant. Statistical analysis was performed using the SPSS $22.0^{\circledR}$ program.

\section{RESULTS}

In the present study, 31 volunteers were evaluated, in which 19 reported patellofemoral pain and 12 no pain, with a mean age of $24.3 \pm 5.6$ years.

Table 1 shows the results for the groups which have pain and the group which did not have pain. The following data were analyzed: lateral tilt, iliac inclination and distance between ASIS.

As verified below, no change was found which represented a significant difference between the analyzed groups for the variables iliac inclination, distance between ASIS. However, the lateral slope variable presented a significant result, with a greater iliac inclination in the volunteers who reported patellofemoral pain. 
Table 2 shows the comparisons between the distance from the ASIS to the right and left lower limb patella, both in the pain group and in the group without pain.

According to the results presented in table 2 and the distance from the ASIS to the patella is the same in the right and left lower limbs in the group with patellofemoral pain. The same result was also found in the group without pain.

Table 3 shows the comparisons between the length of the right and left lower limbs in both groups.

As observed in table 3 , in both groups, no significant differences were found in the lengths of the lower limbs, thus, according to these results, it may be affirmed that the sample did not present lower limb dysmetria.

\section{DISCUSSION}

Patellofemoral pain syndrome (PFPS) is a highly-studied disease, regarding to treatment and its etiology, but there are still few studies which relate PFPS to any changes which may occur in the hip, regarding the musculature and bone morphology. Thus, it is a complex and convenient search for the elucidation of the disease.

In the present study, two groups were used, one group with anterior knee pain and another group which did not report pain (Control group).

No statistical result represented significant alterations, except for the lateral inclination of the pelvis, thus, the pelvis of the individuals with pain has a greater slope compared

TABLE 1. Comparison between variables between groups, using the $t$ test $(\mathrm{N}=31)$.

\begin{tabular}{lccc}
\hline & $\begin{array}{c}\text { Group with } \\
\text { pain }\end{array}$ & $\begin{array}{c}\text { Group without } \\
\text { pain }\end{array}$ & P value \\
\hline Lateral inclination & $2.8 \pm 1.2 \mathrm{~cm}$ & $1.7 \pm 1.3 \mathrm{~cm}$ & $0.03^{*}$ \\
Iliac inclination & $15.2 \circ \pm 4.4$ & $16.0 \circ \pm 3.3 \circ$ & 0.33 \\
Distance between ASIS & $28.5 \pm 1.5 \mathrm{~cm}$ & $25.8 \pm 2.4 \mathrm{~cm}$ & 0.49 \\
\hline
\end{tabular}

$*_{p}<0.05$

TABLE 2. Comparison between the distances from ASIS to patella of both limbs by means of the $t$ test $(\mathrm{N}=31)$.

\begin{tabular}{lccc}
\hline & $\begin{array}{c}\text { Distance ASIS } \\
\text { to patella - RLL }\end{array}$ & $\begin{array}{c}\text { Distance ASIS } \\
\text { to patella - LLL }\end{array}$ & p value \\
\hline Group with pain & $45.0 \pm 3.1 \mathrm{~cm}$ & $44.2 \pm 3.0 \mathrm{~cm}$ & 0.37 \\
Group without pain & $44.6 \pm 2.1 \mathrm{~cm}$ & $45.3 \pm 2.1 \mathrm{~cm}$ & 0.35 \\
\hline
\end{tabular}

$\mathrm{RLL}=$ Right lower limb. $\mathrm{LLL}=$ Left lower limb

TABLE 3. Comparison between the length of the lower limbs of both groups by means of the t test $(\mathrm{N}=31)$.

\begin{tabular}{lccc}
\hline & Length RLL & Length LLL & p value \\
\hline Group with pain & $85.9 \pm 5.4 \mathrm{~cm}$ & $85.4 \pm 5.5 \mathrm{~cm}$ & 0.45 \\
Group without pain & $85.1 \pm 3.4 \mathrm{~cm}$ & $85.9 \pm 3.2 \mathrm{~cm}$ & 0.94 \\
\hline
\end{tabular}

$\mathrm{RLL}=$ Right lower limb. $\mathrm{LLL}=$ Left lower limb to the individuals without pain. This finding does not match information in the literature, so it is suggested that this occur due to some reasons related to muscular issues, which is, muscles with fixations in the pelvic bones in which when retracted or weak, promote the destabilization of the pelvis.

According to Nakagawa et al. ${ }^{(11)}$ PFPS is related to the weakness of the abductor muscles (gluteus medius, gluteus maximus, Tensor fasciae latae). Such muscles have fixation in the iliac bone of the pelvis and when weak they may destabilize allowing consequent pelvic elevation. Thus, It may justify the finding with the present study, in which were found the significant results of lateral tilt of the pelvis with PFPS.

The cited author also states that weakness of medial rotator muscles of the hip may be predisposing factors to PFPS, these muscles have fixation in the ischium and although their fixations are centralized in the pelvis, they may also contribute to the pelvis raise, consequently the lateral inclination occurs.

Gramani-Say et al. ${ }^{(12)}$ agree with the findings of Nakagawa et al. (11), and also suggest that among the hip muscles, the gluteus maximus in a state of weakness is also the generator of PFPS. The gluteus maximus muscle is located in the region close to the other gluteal muscles, referenced and, thus, they may allow the elevation of the homolateral pelvic with consequent inclination of the pelvis.

It is easier to understand the weakness of the external rotator muscles of the hip in PFPS when it is related to the concept of the $Q$ angle, which it formed by the resulting interaction of two forces acting on the patella: the quadriceps force vector and the patellar tendon force vector. The physiological alignment of the lower limb is a pre-disposing factor for patella lateralization, by the forces directing it laterally. Any factor that increases the obliquity of these force vectors may increase the force resulting from lateralization of the patella. ${ }^{(11)}$

Nakagawa et al. ${ }^{(11)}$ also suggest that excessive femoral adduction during dynamic activities may result in weakening of the abductor muscles of the hip, especially the gluteus medius, upper fibers of the gluteus maximus and also the tensor fasciae latae. They also affirm that the adduction and medial rotation of the femur during the functional activities causes an increase of the angle $Q$, which generates a high pressure in the lateral part of the patellofemoral joint which triggers patellofemoral pain.

The present study showed a variation in relation to the lateral inclination of the pelvis. Several muscles acting on the hip and knee in their possible imbalances may cause changes which trigger PFPS.

The iliotibial tract and the tensor fasciae latae, if they are shortened, retracted, will promote pelvic depression and increase lateralisation force of the patella, when retracted also promote the ipsilateral lateral pelvic inclination. ${ }^{(11)}$ This is also possible to be verified in out results.

Tyler et al. ${ }^{(13)}$ also stated that the shortening of tensor fasciae latae muscle may predispose to PFPS, because its 
fibers have the insertion in the lateral facet of the patella, if they are shortened, laterally pull the patella, which increases the stress on the patella. The tensor fasciae latae muscle has fixation in the iliac on its lateral border, in which if it is retracted might promote inferior traction of this bone and culminated with pelvic tilt.

The present study has shown alterations only in relation to the pelvic lateral inclination, and based on the citations of the authors, it is possible to elucidate, in part, that there might be a possible case of shortening of the iliotibial tract and tensor fasciae latae in the volunteers of the group with pain as well as gluteal weakness. Thus, it becomes another hypothesis to be considered in individuals with PFPS.

It may also be observed in the studied group that individuals with PFPS do not present alterations in the distance from ASIS to patella, nor do they present dysmetria of the lower limbs. First, such factors could be possible causal factors of the syndrome since a smaller distance between patella and ASIS could indicate retraction of the rectus femoris muscle, and when shortened it would exert an upward traction force on the patella promoting an increased friction with the trochlear groove. Asymmetry of the limbs could be an indicative of muscular alterations in these subjects, since the positioning of the muscular fixations would be altered, promoting possible joint imbalances throughout the lower limb.

\section{CONCLUSION}

Through the carried-out research, with the studied sample, it is possible to concluded that in this group of volunteers there are few relationships between hip morphology and PFPS, because through the analyzes performed, it was possible to note only a change in lateral inclination of the pelvis in the volunteers of the group who reported anterior knee pain.

It should also be noted that the other data evaluated did not present results that could correlate PFPS with morphological alterations of the pelvis. However, further studies on the subject are suggested, for example, using imaging exams which could gain greater clarity about the pelvic morphology.

\section{AUTHOR'S CONTRIBUTION}

HMS: orientation, review, statistical analysis; LRC: data collection, revision, manuscript preparation; BSB: bibliographic search, revision, manuscript preparation; EGMS: orientation, review, manuscript preparation; JPMJ: orientation, review, manuscript preparation.

\section{CONFLICTS OF INTEREST}

The authors declare that there was no conflict of interest.

\section{AUTHOR DETAILS}

2. Physiotherapist, Rio Verde (GO), Brazil. 3. Undergraduate student of Medicine Course, Rio Verde University (UNIRV), Rio Verde (GO), Brazil. 4. PhD in Health Sciences, Professor at the Federal University of Goias, Brazil. 5. PhD in Applied Physics in Medicine and Biology, Professor at Rio Verde University (UNIRV), Rio Verde (GO), Brazil.

\section{REFERENCES}

1- Andrews, WH. Reabilitação Física das Lesões Desportivas, SP, Guanabara koogan, 2002.

2- Gould. Fisioterapia na Ortopedia e na Medicina do Esporte. $2^{\circ}$ ed., Manole, 1993.

3- Neumann. Cinesiologia do aparelho músculo esquelético - Fundamentos para a Reabilitação Física. Guanabara Koogan, Rio de Janeiro, 2006.

4- Pulzatto F, Gramani-Say K, Siqueira ACB, Santos GM, Bevilaqua-Grossi D, Oliveira AS, et al. A influên'cia da altura do step no exercício de subida posterior: estudo eletromiográfico em indivíduos sadios e portadores da síndrome da dor femoropatelar. Acta ortop. Brás. 2005;13(4):168-170.

5- Cabral CMN, Melim AMO, Sacco ICN, Marques AP. Fisioterapia em pacientes com síndrome femoropatelar: comparação de exercícios em cadeia cinética aberta e fechada. Acta. Ortop. Brás. 2008;16(3):180-185.

6- Moreira E Russo. Cinesiologia clínica e funcional. $1^{\circ}$ ed, Atheneu, São Paulo, Rio de Janeiro, Ribeirão Preto e Belo Horizonte, 2007.

7- Mascal CL, Landel R, Powers C. Management of Patellofemoral Pain Targeting Hip, Pélvis, and Trunk Muscle Funcition: 2 Case Reports. J Orthop Sports Phys Ther. 2003 Nov;33(11):647-60.

8- Ireland ML, Willson JD, Ballantyne BT, Davis IM. Hip Strength in Females With and Without Patellofemoral Pain. J Orthop Sports Phys Ther. 2003;33(11):671-676.

9- Powers CM. The influence of Altered Lower-Extremity Kinematics on Patellofemoral Joint Dysfunction: A Theoretical Perspective. Journal of Orthopaedic \& Sports Physical Therapy. 2003;33(11):639-646.

10- Sanchez HM, Sanchez EGM, Nascimento SV. Association between patellofemoral pain syndrome and hip morphology. Man. Ther., Posturology Rehabil. J., 13:1-6, 2015.

11- Nakagawa TH, Muniz TB, Baldon RM, Serrão FV. A abordagem funcional dos músculos do quadril no tratamento da síndrome da dor femoropatelar. Fisiotr. Mov. 2008;21(1):65-72.

12- Gramani-Say K, Pulzatto F, Santos GM, Vassimon-Barroso V, Siriani de Oliveira A, Bevilaqua-Grossi D, et al. Efeito da rotação do quadril na síndrome da dor femoropatelar. Rev. bras. fisioter. 2006;10(1):75-81.

13- Tyler TF, Nicholas SJ, Mullaney MJ, McHugh MP. The role of hip muscle function in the treatment of patellofemoral pain syndrome. Am J Sports Med. 2006;34:1-7 